\title{
A evolução do gasto-médio/aluno e custo-médio/aluno da rede federal de educação profissional, científica e tecnológica
}

\author{
The evolution of average spending/student and average-cost/student of the \\ federal network of professional, scientific and technological education \\ La evolución del gasto promedio / estudiante y costo promedio / estudiante de \\ la red federal de educación profesional, científica y tecnológica
}

JOSUÉ VIDAL PEREIRA

\begin{abstract}
Resumo: Este artigo tem como objetivo apresentar a dinâmica do gasto/aluno e do custo/aluno da Rede Federal de EPCT entre os anos de 2009 e 2016. Para a identificação do valor do gasto/aluno procedeu-se à divisão do total dos recursos da Rede pelo número de estudantes matriculados. Para o custo-aluno foi utilizada uma modelagem elaborada por Amaral e Pinto (2005), para a determinação do quantum de recursos aplicados no Ensino, para então dividir pelo total das matrículas. Identificou-se duas tendências, a primeira entre 2009 e 2014, na qual se observou uma elevação dos indicadores e a segunda de 2015 a 2016 de retração, determinada pela crise financeira do Estado em face das disputas pelos recursos do fundo público.
\end{abstract}

Palavras-chave: RFEPCT; Gasto-médio/aluno; Custo-médio/aluno; Educação Profissional.

\begin{abstract}
The objective of this article is to present the indicators of expenditure and cost per student of the Federal Network of EPTC from 2009 to 2016. To identify the expenditure/student indicator, the total resources of the Network were divided by the number of students enrolled. To identify the cost-student, a model was elaborated by Amaral and Pinto (2005) to determine the quantum of resources applied in the Teaching, to then divide by the total of enrollments. Two trends were identified, the first between 2009 and 2014, where there was an increase in the indicators and the second from 2015 to 2016 of retraction, determined by the financial crisis of the State in the face of disputes over resources of the public fund.
\end{abstract}

Keywords: RFEPCT; Average expenditure/student; Average-cost/student; Professional Education.

Resumen: Este artículo tiene por objetivo presentar la dinámica de gasto/ estudiante y de costo/estudiante de la Red Federal de Educación Profesional y Tecnológica de Brasil (EPCT) entre los años 2009 y 2016. Para la identificación del valor de gasto/estudiante, se procedió a la división de lo total de los recursos de la Red por el número de estudiantes matriculados. Para el costo/estudiante, fue 
utilizado un modelo elaborado por Amaral y Pinto (2005), para la determinación de la cantidad de recursos aplicados en la Enseñanza, para entonces dividirla por el total de las inscripciones. Se identificaron dos tendencias, la primera entre 2009 y 2014, en la que se observó una elevación en los indicadores y la segunda de 2015 a 2016 de retracción, determinada por la crisis financiera del Estado ante las disputas por los recursos del fondo público.

Palabras clave: Red Federal de EPCT; Gasto-promedio/estudiante; Costopromedio/estudiante; Educación Profesional.

\section{INTRODUÇÃO}

A Rede Federal de Educação Profissional, Científica e Tecnológica (RFEPCT) foi criada por meio da Lei $\mathrm{n}^{\circ}$ 11892, de 29 de dezembro de 2008, através da reestruturação da antiga Rede Federal de Educação Profissional e Tecnológica. Essa mesma lei determinou a mudança de institucionalidade da quase totalidade dessas instituições, que passaram a denominar-se Instituto Federal de Educação, Ciência e Tecnologia. Apenas os Centros Federais de Educação Tecnológica de Minas Gerais e do Rio de Janeiro, além do Colégio Pedro II e Universidade Tecnológica Federal do Paraná mantiveram suas antigas estruturas legais e respectivas denominações. Foram criados 38 Institutos Federais, com capilaridade em todo o território nacional.

No documento 'Um novo modelo em educação profissional e tecnológica: concepções e diretrizes' (Brasil, 2010), o advento dos Institutos Federais é apresentado como uma nova fase para a educação profissional e tecnológica do país. O texto oficial afirma que essa nova institucionalidade da RFEPCT se constitui como parte de um projeto de enfrentamento das desigualdades estruturais tão marcantes na sociedade brasileira.

Segundo o referido texto, os IFs concebidos como política pública buscariam romper com a lógica funcionalista da educação profissional brasileira, historicamente organizada em função da acumulação do capital. Embora reconheça a legitimidade de uma atuação voltada à formação de recursos humanos necessários ao desenvolvimento econômico, os Institutos Federais deveriam assumir importante papel social, tendo em vista alcançar importantes parcelas da população, excluídas das oportunidades de desenvolvimento socioeconômico.

Uma das estratégias concebidas no Projeto dos IFs, tendo em vista seu papel social, tem a ver com sua distribuição por todo o território nacional, com presença nas cidades-polo de cada microrregião do país. O pressuposto, segundo o documento mencionado, seria uma forte atuação na perspectiva do desenvolvimento regional e local, que é condicionado pelo domínio e pela produção do conhecimento científico e cultural. Nesse sentido, mesmo as regiões 
mais atrasadas do ponto de vista do desenvolvimento econômico, poderiam, por meio da ação dos IFs, vislumbrar a possibilidade de exploração de seu potencial econômico, de sua vocação produtiva.

Passados dez anos de criação da nova Rede Federal de EPCT, verificase um movimento consistente de atendimento no campo da modalidade de Educação Profissional e Tecnológica em todos os níveis. Em 2008, portanto, no último ano anterior à reestruturação, segundo o Censo da Educação Básica de 2008 (INEP, 2008), a antiga Rede registrava o total de 77.074 matrículas em nível Técnico e, de acordo com o Censo da Educação Superior do mesmo órgão (INEP, 2008), 40.935 matrículas nos cursos de graduação.

Os dados da Plataforma Nilo Peçanha, do Ministério da Educação, mostram que em 2018 a Rede Federal de Educação Profissional, Científica e Tecnológica registrou 1.031.798 matrículas em todos os níveis, das quais 564.095, ou $54,67 \%$, em cursos técnicos de nível médio, e 261.181, ou 25,31\%, em cursos de Graduação, com atuação marcante também na Qualificação Profissional e na Pós-Graduação, com 106 cursos de Mestrado e sete de doutorado, revelando, portanto, uma ampliação substancial no atendimento em todos os níveis.

Este texto constitui parte dos resultados da pesquisa de doutoramento do autor, concluído em 2018, realizado no Programa de Pós-Graduação em Educação da Universidade Federal de Goiás, sob a orientação do professor Nelson Cardoso Amaral, cujo objeto é o Financiamento da Rede Federal de EPCT. No estudo (PEREIRA, 2018), verificou-se que a totalidade dos recursos aplicados na Rede registrou (em preços atualizados pelo IPCA de janeiro de 2017) em 2008, $\mathrm{R} \$ 4.528 .423,00$ e, em 2016 - o último ano do levantamento, $\mathrm{R} \$$ 12.238.690,00, quase triplicando, portanto, o valor identificado no primeiro ano.

Dada a intensidade do movimento de expansão da aplicação de recursos do Fundo Público verificado no período de 2009 a 2016, bem como o espetacular movimento de expansão do atendimento, conforme assinalado acima, este artigo tem como objetivo apresentar a dinâmica do gasto-médio/aluno e do custo-médio/aluno da Rede nesse intervalo temporal. Trata-se, portanto, de um esforço em nível de um estudo de tipo exploratório, cujos dados foram levantados a partir de pesquisa documental, sobretudo por meio dos relatórios produzidos e disponibilizados para consulta pública pelos bancos de dados da Execução Orçamentária da União, hospedados no sítio eletrônico da Câmara dos Deputados. 


\section{CONSIDERAÇÕES METODOLÓGICAS}

Em face dos objetivos do presente estudo, considera-se importante a utilização de uma modelagem a partir da qual se possa determinar o quantum de recursos são aplicados por aluno matriculado ano a ano desde a estruturação da Rede Federal de Educação Profissional, Científica e Tecnológica em 2009. Excluise desse cálculo o Colégio Pedro II, que, embora seja membro da RFEPCT, não oferta cursos Técnicos Integrados ao Ensino Médio como também cursos superiores.

Para a apuração do gasto médio anual, procede-se a uma simples operação de divisão do total dos recursos da Rede pelo quantitativo de alunos matriculados em todas as modalidades, exceto em cursos de especialização lato sensu e de formação inicial e continuada de trabalhadores.

Em relação ao custo médio anual, dada a complexidade das variáveis e da diversidade de elementos de despesas que constitui a totalidade dos recursos orçamentários das instituições da Rede, é necessária a utilização de uma modelagem que considere as especificidades da aplicação dos recursos. Uma modelagem somente não seria necessária se os valores executados no âmbito das instituições estivessem separados nas vertentes do ensino, da pesquisa e da extensão; se no salário dos trabalhadores já estivesse especificado qual parte é relativa às atividades de ensino. qual é relativa à pesquisa e qual se relaciona às atividades de extensão. $\mathrm{O}$ mesmo fatiamento deveria ocorrer com todas as despesas relativas às outras despesas correntes (água, luz, telefone, material de consumo etc.) e de capital (obras e instalações, equipamentos etc.). Esse fatiamento é de difícil operacionalização e de custo muito elevado, o que inviabilizaria sua implementação pelas instituições.

A modelagem proposta neste trabalho, para que se possa determinar o custo médio do aluno da RFEPCT, foi elaborada por Amaral e Pinto (2005) para a análise do financiamento das instituições públicas e privadas de educação superior brasileiras no ano de 2005. É uma atividade ainda a ser realizada, e um desafio à elaboração de uma modelagem específica para as instituições da Rede, que considere as diversidades internas e externas existentes, em seu conjunto. Portanto, os cálculos desse estudo significam uma primeira aproximação, que pode ser considerada válida, pela completa inexistência de análises dessa natureza na literatura.

Os autores do estudo supracitado advertem para as simplificações utilizadas para a efetivação de cálculos de custo-aluno nas instituições de ensino superior brasileiras. "Muita confusão [...] se faz presente nessa discussão quando simplesmente se divide o gasto total da instituição pelo número de estudantes da graduação" (p. 61). Nesse sentido, afirmam a incoerência de se estabelecerem 
comparações entre IES que desenvolvem atividades voltadas ao ensino, pesquisa e extensão com forte atuação comunitária por meio de hospitais, teatros, museus etc. com outras envolvidas basicamente com a oferta de cursos superiores e com baixos níveis de atuação na comunidade.

Analogamente, ressalvadas as devidas proporções, o mesmo se pode afirmar em relação a possíveis comparações de gasto médio e custo médio do aluno da Rede Federal de EPCT em relação às redes privadas de Educação Profissional do país. Primeiramente porque as redes privadas tendem a concentrar suas ofertas em cursos de baixas cargas horárias e baixo nível tecnológico. Também se verificou que é na Rede Federal onde estão os maiores percentuais de atendimento em cursos Técnicos Integrados, como também razoável percentual de matrículas em cursos de licenciaturas, engenharias e bacharelados.

Ao mesmo tempo, as redes privadas, a exemplo do Sistema Nacional de Aprendizagem, têm nos cursos de Formação Inicial e Continuada seu grande foco de atuação no nível técnico; sua atuação se concentra em cursos do tipo subsequente, ou seja, desvinculados da formação geral, cujo custo é muito mais reduzido. Mesmo quando atuam na Educação Superior, as redes privadas de Educação Profissional tendem a concentrar suas ofertas em cursos de curta duração, do tipo Cursos Superiores de Tecnologia (CST).

Também se deve assinalar que, como reflexo de bons percentuais de professores com títulos de pós-graduação stricto sensu, a Rede Federal promove o desenvolvimento de pesquisas científicas aplicadas, como também desenvolve atividades de interação comunitária por meio de programas de extensão e cultura.

Desse modo, somente por meio de uma modelagem que seja capaz de atribuir distintamente o valor para cada dimensão da atuação das instituições de EPCT da Rede Federal, tais como Ensino e (Pesquisa + Extensão), será possível chegar ao valor aproximado do custo médio por aluno. A modelagem proposta por Amaral e Pinto (2005) considera necessárias para o estabelecimento do cálculo do custo médio anual do aluno, as seguintes premissas:

1) Existe uma relação direta entre as despesas com pesquisa ou extensão e a quantidade de professores que trabalham em tempo integral nas instituições. Consideraremos nesta modelagem que os percentuais apurados nos itens 2, 3 e 4, a seguir, serão multiplicados por um fator que os relativize em relação ao percentual de professores em tempo integral (Fator Tempo Integral - FTI). O FTI será igual à fração de professores em tempo integral em relação ao total de professores das instituições. Então se, por exemplo, $72 \%$ dos professores estão em tempo integral, o FTI associado será de 0,72. [...] 2) Existe uma relação direta entre o percentual das despesas que se destinam à pesquisa ou à extensão e o número de mestres e doutores. A categoria [...] que tiver $100 \%$ de seus professores com titulação de mestre ou doutor dedicará $50 \%$ de suas despesas para pesquisa ou extensão e aplicará $0 \%$ em pesquisa ou extensão se tiver nenhum de seus professores com 
essas titulações, relativizadas pelo FTI. Valores entre 0\% e 100\% de professores mestres ou doutores significarão, proporcionalmente, gastos com pesquisa ou extensão, entre $0 \%$ e $50 \%$, relativizados pelo FTI. [...] 3) Existe uma relação direta entre as despesas com pesquisa ou extensão e o percentual de alunos de pós-graduação stricto sensu em relação ao total de alunos das instituições [...]. A modelagem deste estudo considera que o percentual de alunos de pós-graduação stricto sensu e o total de alunos será o percentual dedicado às atividades de pesquisa ou extensão relativizados pelo FTI que deve ser adicionado ao percentual anterior. [...] 4) Existe uma relação direta entre as despesas com pesquisa ou extensão e a avaliação da Capes de seus programas de pós-graduação stricto sensu. Essa modelagem considera que, se a média do conceito Capes dos programas de pósgraduação for igual a sete, 10\% dos recursos das instituições se dirigem à pesquisa ou à extensão relativizados pelo FTI; se a média for menor ou igual a três, 3\% dos recursos se dirigem à pesquisa ou à extensão relativizados pelo FTI. Valores médios do conceito Capes entre três e sete significarão, proporcionalmente, gastos com pesquisa ou extensão entre 3\% e 10\% relativizados pelo FTI. O percentual apurado neste item deve ser adicionado aos percentuais dos itens 1 e 2. [...] Nessa modelagem o maior valor para os gastos com pesquisa ou extensão ficaria com aquele conjunto de instituições [...] que satisfizesse simultaneamente as seguintes condições: 1) possuísse o maior percentual de professores em tempo integral, 2) todos os docentes fossem mestres ou doutores, 3) possuísse o maior número relativo de alunos de mestrado e doutorado entre os alunos das instituições e 4) possuísse o maior valor para a média do conceito Capes. (AMARAL; PINTO, 2005, p. 62-63).

Conforme lembram os autores, as Instituições Federais de Educação possuem despesas não relacionadas diretamente ao ensino, à pesquisa ou à extensão. No caso específico da Rede Federal de EPCT, destacam-se: o pagamento de inativos e pensionistas, assistência pré-escolar dos filhos dos servidores públicos, manutenção de restaurantes para alunos, assistência médica e odontológica e precatórios.

\section{APURAÇÃO DO GASTO-ALUNO E DO CUSTO-ALUNO DA REDE FEDERAL DE EPCT}

A efetivação dos cálculos para obtenção do custo médio do aluno da Rede Federal sem distinção de modalidade de matrícula requer, para além dos percentuais estabelecidos nos itens 1 a 4, conforme explicitado anteriormente, a subtração do total das despesas do conjunto das instituições, a totalidade do gasto com o pagamento de inativos e pensionistas e o pagamento de exercícios anteriores, uma vez que tais despesas não se relacionam ao efetivo funcionamento das instituições federais de educação profissional. 
Tem-se, portanto, segundo a modelagem proposta, que o valor líquido dos recursos financeiros da Rede Federal de EPCT aplicados na totalidade dos cursos ofertados, resultarão da subtração do total das despesas da Rede de um percentual destinado às atividades de pesquisa e extensão, como também do pagamento de inativos e pensionistas e exercícios anteriores. Por sua vez a composição do percentual que se destina às atividades de pesquisa e extensão resulta de uma combinação de quatro componentes articulados, quais sejam: o percentual de docentes em tempo integral, o quantitativo de mestres e doutores relativizados pelo total de professores, o percentual de estudantes de pós-graduação stricto sensu relativizados pelo total de alunos da Rede e o conceito médio Capes dos programas de pós-graduação stricto sensu do conjunto das instituições.

A tabela 1 apresenta a apuração do Fator 'Tempo Integral', resultante da relativização do total de Funções de Tempo Integral pelo total de funções docentes, ou seja, quanto maior o percentual de funções docentes em relação ao seu total, maior será o Fator de Tempo Integral, conforme se observa na referida tabela.

Tabela 1 - Fator de Tempo Integral (FTI) a ser utilizado (2009-2016)

\begin{tabular}{|c|c|c|c|c|}
\hline Ano & $\begin{array}{c}\text { Total de Funções } \\
\text { Docentes }\end{array}$ & $\begin{array}{c}\text { Total de Funções } \\
\text { em Tempo Integral }\end{array}$ & $\%$ & $\begin{array}{c}\text { Fator de Tempo } \\
\text { Integral (FTI) }\end{array}$ \\
\hline 2009 & 8.796 & 7.821 & 88 & 0,88 \\
\hline 2010 & 10.786 & 9.219 & 85 & 0,85 \\
\hline 2011 & 12.930 & 11.128 & 86 & 0,86 \\
\hline 2012 & 15.879 & 13.548 & 85 & 0,85 \\
\hline 2013 & 17.846 & 15.487 & 86 & 0,86 \\
\hline 2014 & 20.039 & 17.957 & 89 & 0,89 \\
\hline 2015 & 21.583 & 19.503 & 90 & 0,90 \\
\hline 2016 & 22.795 & 20.559 & 90 & 0,90 \\
\hline
\end{tabular}

Fonte: Censo da Educação Superior (2009-2016)

A tabela 2 apresenta a participação em percentual de portadores de títulos de mestrado e doutorado em relação ao total das funções docentes da Rede Federal de EPCT para o período de 2009 a 2016. Os percentuais apurados, conforme explicitados nesta tabela serão adicionados posteriormente adicionados aos demais componentes de constituição de despesas, para a identificação do percentual destinado à pesquisa e extensão das Instituições. 
Tabela 2 - Peso das atividades de pesquisa e extensão por exercício, considerando a titulação dos docentes e do FTI (2009-2016)

\begin{tabular}{|c|c|c|c|c|c|}
\hline Ano & $\begin{array}{c}\text { Total de Funções } \\
\text { Docentes }\end{array}$ & $\begin{array}{c}\text { Total de Ms } \\
\text { ou Dr }\end{array}$ & $\begin{array}{c}\% \text { Ms } \\
\text { ou Dr }\end{array}$ & FTI & \% Pes Ext Ms + Dr \\
\hline 2009 & 8.796 & 4.590 & 52 & 0,88 & 22,88 \\
\hline 2010 & 10.786 & 7.454 & 69 & 0,85 & 29,32 \\
\hline 2011 & 12.930 & 9.148 & 70 & 0,86 & 30,10 \\
\hline 2012 & 15.879 & 11.434 & 72 & 0,85 & 30,60 \\
\hline 2013 & 17.846 & 13.446 & 75 & 0,86 & 32,25 \\
\hline 2014 & 20.039 & 15.777 & 78 & 0,89 & 34,71 \\
\hline 2015 & 21.583 & 17.789 & 82 & 0,90 & 36,90 \\
\hline 2016 & 22.795 & 18.779 & 82 & 0,90 & 36,90 \\
\hline
\end{tabular}

Fonte: Censo da Educação Superior (INEP, 2009-2016)

$\mathrm{Na}$ tabela 3, apresentada a seguir, explicita-se a participação do componente Percentual de Estudantes de Pós-Graduação stricto sensu, obtido a partir da relativização do número de estudantes dessa categoria pelo total dos estudantes de cursos técnicos/integrados e graduação multiplicados pelo FTI. Deve-se, contudo, ressaltar que a apuração do quantitativo de estudantes matriculados na RFEPCT resulta numa reduzida margem de imprecisão - com baixo impacto no cálculo do custo-aluno e gasto-aluno, dado pela metodologia de divulgação do Censo da Educação Básica pelo INEP, o qual inclui na categoria "Educação Profissional Federal" os estudantes matriculados nas Escolas Técnicas vinculadas às Universidades Federais. Ou seja, para a apuração da totalidade das matrículas na Rede Federal de EPCT, é necessário subtrair do total das matrículas da "Educação Profissional Federal" o total das matrículas registrado nas "Escolas Técnicas Vinculadas" que, portanto, não integram a RFEPCT. 
Tabela 3 - Peso das atividades de pesquisa e extensão por exercício, considerando a presença de estudantes de Pós-graduação stricto-sensu (2009-2016)

\begin{tabular}{|c|c|c|c|c|c|}
\hline Ano & $\begin{array}{c}\text { Est. de Técnico e } \\
\text { Graduação }\end{array}$ & $\begin{array}{c}\text { Estudantes } \\
\text { de pós- } \\
\text { graduação } \\
\text { (Ms e Dr) }\end{array}$ & \% Est. Pós. & FTI & $\begin{array}{c}\text { \% PES EXT } \\
\text { Est.Pós }\end{array}$ \\
\hline 2009 & 226.662 & 966 & 0,43 & 0,88 & 0,38 \\
\hline 2010 & 291.756 & 1.179 & 0,41 & 0,85 & 0,35 \\
\hline 2011 & 325.529 & 1.514 & 0,45 & 0,86 & 0,39 \\
\hline 2012 & 356.956 & 1.870 & 0,52 & 0,85 & 0,44 \\
\hline 2013 & 383.411 & 2.225 & 0,58 & 0,86 & 0,49 \\
\hline 2014 & 391.311 & 2.838 & 0,72 & 0,89 & 0,64 \\
\hline 2015 & 465.866 & 3.704 & 1,00 & 0,90 & 0,90 \\
\hline 2016 & 531.417 & 4.707 & 0,9 & 0,90 & 0,81 \\
\hline
\end{tabular}

Fonte: Censo da Educação Básica (INEP, 2009-2016); Censo da Educação Superior (INEP, 20092016)

Neste estudo a identificação do total de matrículas das Escolas Técnicas Vinculadas se deu a partir dos Relatórios de Gestão das Universidades, disponíveis no sítio eletrônico do Tribunal de Contas da União ${ }^{1}$. Entre os anos de 2009 e 2013 , não é possível apurar com precisão os dados de matrículas das Escolas Vinculadas ofertantes de Educação Profissional, devido à falta de padronização no modo de divulgação dos dados, que, em diversos relatórios, aparecem totalizados de modo indiscriminado, incluindo por exemplo matrículas de Colégios de Aplicação das UFs, os quais ofertam apenas Ensino Médio. A partir de 2014, por exigência do TCU, tais relatórios já apresentam as matrículas em EP do modo sistematizado na ação 20RL, que permite identificar com precisão os números da Educação Profissional. Desse modo, este estudo subtraiu do total de matrículas da "Educação Profissional Federal" as matrículas das Escolas Técnicas Vinculadas apenas para os anos de 2014 a 2016, ficando as matrículas dos anos de 2009 a 2013 incluídas nos cálculos de custo-aluno e gasto aluno da Rede Federal. No entanto, conforme observado nos últimos três anos da pesquisa, a totalidade das matrículas nas vinculadas não passam de 3\% do total das matrículas na Educação Profissional Federal. Em 2014 e 2015 as mesmas registram 3\% de participação no total, enquanto em 2016 esse percentual cai para $2 \%$, o que, do ponto de vista deste estudo não inviabiliza a elaboração do cálculo de custo-aluno e gasto-aluno, conforme será apresentado posteriormente. 
A tabela 4 apresenta a participação do componente 'Conceito Capes' dos programas de Pós-graduação stricto sensu da Rede Federal de EPCT, resultante do levantamento das médias obtidas pelos programas na avaliação da Coordenação de Aperfeiçoamento de Pessoal de Nível Superior do Ministério da Educação entre os anos de 2009 e 2016. O percentual obtido nesse componente será adicionado aos dois anteriores para fins de identificação do Percentual do Orçamento da Rede aplicados em Pesquisa e Extensão.

\section{Tabela 4 - Peso das atividades de pesquisa e extensão por exercício, considerando a conceituação da Capes (2009-2016)}

\begin{tabular}{|c|c|c|c|c|}
\hline Ano & $\begin{array}{c}\text { Conceito médio } \\
\text { Capes }\end{array}$ & $\begin{array}{c}\% \text { Capes entre 3\% } \\
\text { e 10\% }\end{array}$ & $\%$ & $\%$ PES EXT Capes \\
\hline 2009 & 3,08 & 3,14 & 0,88 & 2,76 \\
\hline 2010 & 3,22 & 3,38 & 0,85 & 2,87 \\
\hline 2011 & 3,16 & 3,28 & 0,86 & 2,82 \\
\hline 2012 & 3,13 & 3,52 & 0,85 & 2,99 \\
\hline 2013 & 3.28 & 3,49 & 0,86 & 3,00 \\
\hline 2014 & 3,20 & 3,35 & 0,89 & 2,98 \\
\hline 2015 & 3,19 & 3,35 & 0,90 & 3,01 \\
\hline 2016 & 3,16 & 3,28 & 0,90 & 2,95 \\
\hline
\end{tabular}

Fonte: Censo da Educação Superior (2009-2016)

A tabela 5 apresenta a agregação dos três componentes constituintes das despesas relacionadas à Pesquisa e a Extensão da Rede Federal de ECPT. A soma dos percentuais de cada componente revela o total dedicado à Pesquisa e Extensão para cada ano do levantamento (2009 a 2016). 
Tabela 5 - Participação total nas despesas das atividades de pesquisa e extensão por exercício (2009-2016)

\begin{tabular}{|c|c|c|c|c|}
\hline Ano & $\begin{array}{c}\text { \% PESQ EXT } \\
\text { Ms + Dr }\end{array}$ & $\begin{array}{c}\text { \% PESQ EXT } \\
\text { Est. Pós }\end{array}$ & $\begin{array}{c}\text { \% PESQ EXT } \\
\text { Capes }\end{array}$ & $\begin{array}{c}\text { \% PESQ EXT } \\
\text { TOTAL }\end{array}$ \\
\hline 2009 & 3,08 & 3,14 & 0,88 & 2,76 \\
\hline 2010 & 3,22 & 3,38 & 0,85 & 2,87 \\
\hline 2011 & 3,16 & 3,28 & 0,86 & 2,82 \\
\hline 2012 & 3,13 & 3,52 & 0,85 & 2,99 \\
\hline 2013 & 3.28 & 3,49 & 0,86 & 3,00 \\
\hline 2014 & 3,20 & 3,35 & 0,89 & 2,98 \\
\hline 2015 & 3,19 & 3,35 & 0,90 & 3,01 \\
\hline 2016 & 3,16 & 3,28 & 0,90 & 2,95 \\
\hline
\end{tabular}

Fonte: Censo da Educação Superior (2009-2016)

De acordo com a tabela 5, cujos cálculos foram realizados seguindo os critérios estabelecidos pela modelagem proposta por Amaral e Pinto (2005), o principal componente para a identificação do percentual dedicado à Pesquisa e Extensão é o número de funções docentes com títulos de mestrado e doutorado. Em segundo lugar em importância, aparece o conceito Capes e, em terceiro, o percentual de estudantes de Pós-graduação stricto sensu.

Os percentuais anuais do total dos Recursos da Rede Federal de ECPT, destinados à Pesquisa e Extensão, conforme explicitado na tabela 5, indicam um movimento ascendente da importância da Pesquisa e Extensão na referida Rede, a qual observa uma tendência de constante aumento da participação dessas atividades desde o ano de 2009 , quando sai de $26,02 \%$ do orçamento para $40,81 \%$ em 2015. Em 2016 registra-se um leve recuo, para 39,76\% de participação.

A média de 35,06\% de participação da Pesquisa e Extensão no total dos recursos aplicados entre os anos do levantamento, localizam a Rede Federal de EPCT na segunda posição do conjunto das Instituições de Educação Superior do País, se considerarmos o levantamento realizado pelo estudo de Amaral e Pinto (2005). Neste, os autores registram para o ano de 2005, o percentual de $42,3 \%$ para as Universidades Federais e 33,6\% para as Universidades Estaduais. Nesse mesmo estudo, as instituições privadas ficaram com $3,7 \%$ e as confessionais e filantrópicas com $6,9 \%$.

No presente estudo, embora o quantitativo de estudantes de Pósgraduação stricto sensu tenha observado um crescimento elevado de quase $400 \%$ no período pesquisado - saltando de 996 em 2009 para 4.707 em 2016 - não se deve perder de vista que o principal fator de constituição do percentual de 
Pesquisa e Extensão é o número de funções docentes com mestrado e doutorado os quais, ao longo desse período, registram um crescimento de $243 \%$ no último ano em relação ao primeiro.

A tabela 6 apresenta a totalização dos recursos excluídos do cálculo do custo-aluno da Rede Federal de Educação Profissional, Científica e Tecnológica entre os anos de 2009 e 2016. Para tanto, foram considerados os percentuais destinados à Pesquisa e Extensão apurados em cada ano do estudo, bem como os recursos direcionados aos aposentados e pensionistas, os quais não constituem despesas relativas ao funcionamento das Instituições. Para fins do cálculo de custo-aluno, os recursos totais apontados nessa tabela serão subtraídos do total do orçamento do conjunto da Rede.

\section{Tabela 6 - Recursos excluídos do cálculo para a obtenção do custo-aluno da Rede Federal de EPCT (2009-2016) - Valores em reais, corrigidos pelo IPCA, a preços de janeiro/2017}

\begin{tabular}{|c|c|c|c|}
\hline Ano & $\begin{array}{c}\text { Aposentados e } \\
\text { Pensionistas }\end{array}$ & Pesquisa e Extensão & $\begin{array}{c}\text { Total dos recursos } \\
\text { excluídos do cálculo do } \\
\text { custo-aluno }\end{array}$ \\
\hline 2009 & $1.112 .642 .541,00$ & $1.447 .842 .201,00$ & $2.560 .484 .742,00$ \\
\hline 2010 & $1.200 .520 .749,00$ & $2.605 .375 .176,00$ & $3.805 .895 .925,00$ \\
\hline 2011 & $1.264 .727 .306,00$ & $3.126 .948 .070,00$ & $4.391 .675 .376,00$ \\
\hline 2012 & $1.276 .467 .551,00$ & $3.555 .929 .910,00$ & $4.832 .397 .461,00$ \\
\hline 2013 & $1.360 .544 .483,00$ & $4.348 .342 .979,00$ & $5.708 .887 .462,00$ \\
\hline 2014 & $1.412 .034 .695,00$ & $5.121 .616 .877,00$ & $6.533 .651 .572,00$ \\
\hline 2015 & $1.448 .887 .059,00$ & $5.349 .710 .123,00$ & $6.798 .597 .182,00$ \\
\hline 2016 & $1.495 .900 .320,00$ & $4.866 .103 .185,00$ & $6.362 .003 .505,00$ \\
\hline
\end{tabular}

Fonte: elaboração do autor com informações da Execução Orçamentária da União e cálculos deste estudo

A tabela 7 apresenta a totalidade dos recursos da Rede Federal de EPCT entre 2009 e 2016, utilizados para a efetivação do cálculo de custo-aluno. O total dos recursos foi obtido pela subtração do total do orçamento do conjunto da Rede pelos recursos excluídos do cálculo, conforme apresentado na tabela 4.10. 
Tabela 7 - Recursos totais utilizados para obtenção do custo-aluno da Rede Federal de ECPT (2009-2016) - Valores em milhares de reais, corrigidos pelo IPCA, a preços de janeiro/2017

\begin{tabular}{|c|c|c|c|}
\hline Ano & $\begin{array}{c}\text { Recursos totais do } \\
\text { Orçamento }\end{array}$ & $\begin{array}{c}\text { Recursos excluídos do } \\
\text { cálculo }\end{array}$ & $\begin{array}{c}\text { Total de Recursos para } \\
\text { o cálculo }\end{array}$ \\
\hline 2009 & $5.564 .343,00$ & $2.560 .484,00$ & $3.003 .859,00$ \\
\hline 2010 & $8.006 .684,00$ & $3.805 .895,00$ & $4.200 .789,00$ \\
\hline 2011 & $9.387 .415,00$ & $4.391 .675,00$ & $4.995 .740,00$ \\
\hline 2012 & $10.450 .287,00$ & $4.832 .397,00$ & $5.617 .890,00$ \\
\hline 2013 & $12.168 .018,00$ & $5.708 .887,00$ & $6.459 .131,00$ \\
\hline 2014 & $13.381 .546,00$ & $6.533 .651,00$ & $6.847 .895,00$ \\
\hline 2015 & $13.110 .490,00$ & $6.798 .597,00$ & $6.311 .893,00$ \\
\hline 2016 & $12.238 .690,00$ & $6.362 .003,00$ & $5.876 .687,00$ \\
\hline
\end{tabular}

Fonte: elaboração do autor com informações da Execução Orçamentária da União e cálculos deste estudo

A tabela 8 apresenta o quantitativo de alunos de cursos de cursos Técnicos/Técnicos Integrados e Graduação da Rede Federal de EPCT entre os anos de 2009 e 2016. Para a obtenção do valor final do custo-aluno, foi realizada a divisão do total de recursos apurados na tabela 7 pelo quantitativo de alunos desta tabela para cada respectivo ano do estudo.

Tabela 8 - Quantitativo de alunos apurados para a efetivação do cálculo de custo-aluno da Rede Federal de EPCT (2009-2016)

\begin{tabular}{|c|c|c|c|}
\hline Ano & $\begin{array}{c}\text { Alunos de cursos } \\
\text { Técnicos e Graduação }\end{array}$ & $\begin{array}{c}\text { Alunos de Pós- } \\
\text { Graduação Stricto- } \\
\text { Sensu }\end{array}$ & $\begin{array}{c}\text { Total de alunos da Rede } \\
\text { Federal de EPCT }\end{array}$ \\
\hline 2009 & 226.662 & 966 & 227.628 \\
\hline 2010 & 291.756 & 1.179 & 292.935 \\
\hline 2011 & 325.529 & 1.514 & 327.043 \\
\hline 2012 & 356.956 & 1.870 & 358.826 \\
\hline 2013 & 383.411 & 2.225 & 385.636 \\
\hline 2014 & 391.311 & 2.838 & 394.149 \\
\hline 2015 & 465.866 & 3.704 & 469.570 \\
\hline 2016 & 531.417 & 4.707 & 536.124 \\
\hline
\end{tabular}

Fonte: Censo da Educação Básica (INEP, 2009-2016); Censo da Educação Superior (INEP, 20092016) 
A tabela 9 apresenta os valores referentes aos dados apurados para a média do gasto médio anual e do custo médio anual dos alunos da Rede Federal de EPCT entre os anos de 2009 e 2016.

Tabela 9 - Gasto médio anual e custo médio anual por aluno da Rede Federal de EPCT (2009 - 2016) - Valores em reais, corrigidos pelo IPCA, a preços de janeiro/2017

\begin{tabular}{|c|c|c|}
\hline ANO & GASTO MÉDIO & CUSTO MÉDIO \\
\hline 2009 & $22.046,00$ & $13.366,40$ \\
\hline 2010 & $25.294,00$ & $14.792,83$ \\
\hline 2011 & $26.905,00$ & $15.193,62$ \\
\hline 2012 & $27.384,00$ & $16.110,00$ \\
\hline 2013 & $29.834,00$ & $17.272,44$ \\
\hline 2014 & $32.255,00$ & $18.032,83$ \\
\hline 2015 & $25.126,00$ & $13.406,88$ \\
\hline 2016 & $22.075,00$ & $11.866,78$ \\
\hline
\end{tabular}

Fonte: Censo da Educação Superior (INEP, 2009-2016) e cálculos deste estudo

Pela metodologia utilizada neste estudo, a apuração do Gasto Médio Anual do aluno da Rede Federal de EPCT consistiu da divisão da totalidade dos recursos aplicados em todos os blocos de despesas pelo quantitativo total dos alunos matriculados em cursos regulares no conjunto das Instituições em determinado ano. Quanto ao Custo Médio Anual, sua identificação se deu mediante a subtração do total do orçamento da Rede pelo percentual destinado à Pesquisa e Extensão, conforme consta na tabela 5, bem como dos recursos destinados aos Aposentados e Pensionistas. O quantum dos recursos apurados nesse cálculo dividiu-se pela totalidade dos estudantes matriculados em todos os cursos regulares do conjunto da Rede.

O gráfico 1 apresenta a dinâmica do Gasto Médio Anual dos alunos da Rede Federal de EPCT, bem como o Custo Médio Anual do estudante para o período de 2009 a 2016. 


\section{Gráfico 1 - Dinâmica do gasto médio e custo médio por aluno da Rede Federal de EPCT (2009-2016) - Valores em reais, corrigidos pelo IPCA, a preços de janeiro/2017}

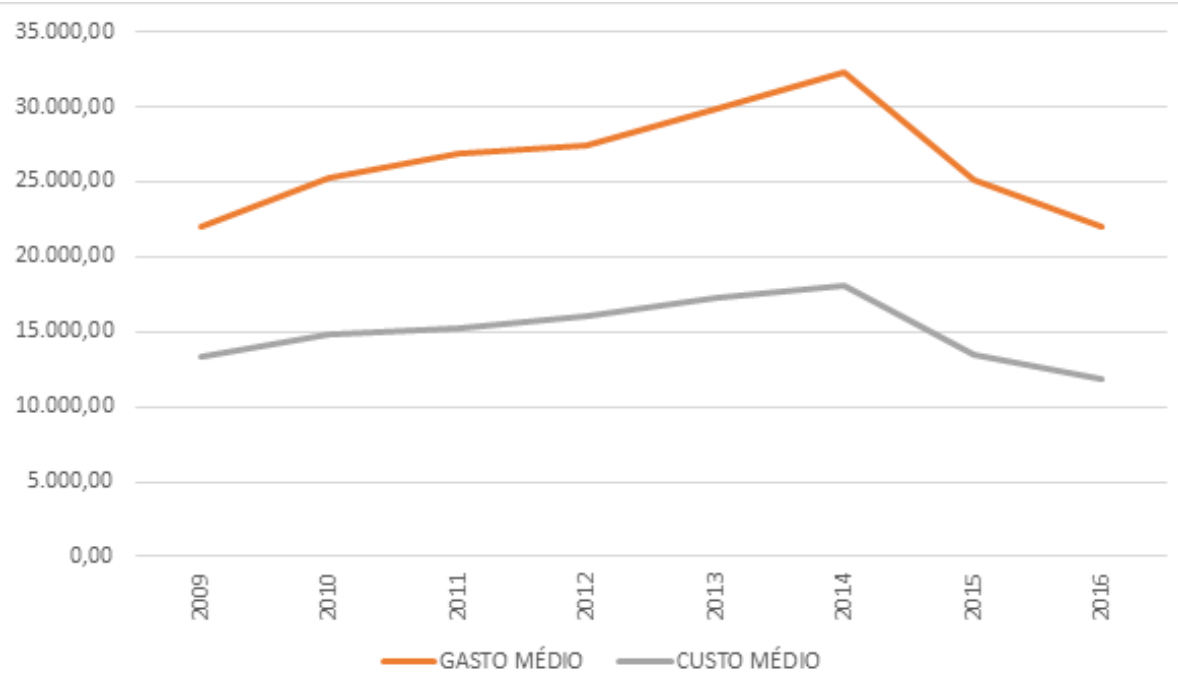

Fonte: Censo da Educação Superior (INEP, 2009-2016) e cálculos deste estudo

Os números apresentados na tabela 9 e gráfico 1, indicam que tanto o Gasto Médio Anual por aluno, quanto o Custo Médio Anual por Aluno sofreram grande variação ao longo do intervalo analisado. O Gasto Médio Anual, por exemplo, registra em 2014 um crescimento de 46,4\% em relação a 2009, enquanto o Custo Médio Anual por aluno matriculado cresce no mesmo período $34,9 \%$. Com a crise econômica a partir de 2015, tem-se uma drástica redução dos recursos da Rede Federal de EPCT, o que implica a consequente queda do Gasto e do Custo Médio anuais dos estudantes, de modo que, em 2016, o Gasto Médio cai 46,1\% enquanto o Custo Médio registra uma redução de 34,3\%, em relação a 2014.

Do ponto de vista da execução orçamentária, o principal fator explicativo para tais oscilações do Gasto e do Custo Médio anuais por estudante matriculado diz respeito aos recursos do bloco de Investimentos. Ou seja, a elevação de tais indicadores está diretamente relacionada com a expansão da Rede, pela elevação fenomenal do gasto com a construção de edificações e aquisição de laboratórios e equipamentos em geral, de modo que entre 2009 e 2013 este bloco de despesas registra um crescimento de $670 \%$, saltando de 222 milhões de reais para 1,7 bilhões de reais. No mesmo período o mais importante bloco de despesas - Pessoal e Encargos Sociais - registra um crescimento bem mais modesto, da ordem de 
$73 \%$, saindo de 4,4 bilhões de reais para 7,7 bilhões de reais. Tal elevação se relaciona diretamente ao aumento do número de pessoal efetivado, sobretudo docentes, que cresceu $114 \%$ no período.

Também a drástica redução do Gasto e do Custo Médio anuais dos estudantes regulamente matriculados na Rede Federal está diretamente relacionada à brusca queda das despesas no bloco de investimentos, os quais desabam de 1,47 bilhões de reais em 2014 para apenas 202 milhões de reais em 2016. Nesse mesmo período, as Despesas Correntes registram uma queda bem mais modesta, de 2,86 bilhões de reais para 2,51 bilhões de reais, e Pessoal e Encargos Sociais registra uma oscilação que sai de 9 bilhões de reais de 2014, elevando o gasto para 10,3 bilhões em 2015 e baixando para 9,51 bilhões de reais em 2016. Contudo, deve-se notar que, não obstante a queda de $8,2 \%$ desse bloco de despesas, observou-se uma elevação de 5,6\% no número de docentes contratados por concurso para o quadro efetivo no ano de 2016.

Tem-se, portanto, que a elevação substancial dos indicadores até o ano de 2014, conforme apresentado na tabela 6, não representa efetivamente uma tendência de sustentação desses valores no longo prazo, uma vez que, tão logo seja concluída a execução dos projetos de edificações e laboratórios, a aplicação de recursos do bloco de investimentos deverá impactar imediatamente na queda do Gasto Médio e do Custo Médio anuais dos alunos regularmente matriculados nas Instituições. Aliás, esse é o fenômeno explicativo da diminuição de tais indicadores nos dois últimos anos da pesquisa, muito embora a redução dos recursos do referido bloco seja explicada por fatores outros, uma vez que ainda não haviam sido concluídas todas as fases da expansão da Rede Federal de EPCT.

Para além das variáveis que impactam diretamente os indicadores de Gasto e Custo Médio anuais de estudantes regularmente matriculados na Rede Federal de EPCT, faz-se necessária uma análise que busque ponderar o significado dos dois indicadores. No entanto, não se trata de uma tarefa simples, uma vez que não se dispõe, na literatura, de estudos de financiamento da Educação Profissional, tanto brasileira quanto internacional, que possam servir de parâmetros.

Dadas as grandes taxas de oscilação observadas na apuração dos indicadores entre os anos de 2009 a 2016, apresentam-se as médias do Gasto e do Custo Médio anuais para os anos da pesquisa. Portanto, a média do Gasto Médio Anual do estudante regularmente matriculado em valores de janeiro de 2017 foi de 26.364,88 reais e a média do Custo Médio Anual do estudante regularmente matriculado foi de 15.005,22 reais. O valor do Custo Médio Anual, ficou, portanto, 21,5\% menor do que o identificado por Amaral e Pinto (2005) para as Universidades Federais para o ano de 2005, que, em valores de janeiro de 2017 (IPCA) era de 18.827,20 reais. 
A comparação do Custo Médio do Aluno da Rede Federal de ECPT com o Custo Médio do Aluno do conjunto das Universidades Federais se justifica, primeiro, porque a metodologia de aplicação para a apuração dos indicadores foi rigorosamente a mesma. conforme indicado no início do texto. Segundo; porque verificam-se importantes aproximações da RFEPCT com as Universidades Federais, tais como: isonomia salarial, progressão e promoção na carreira entre o Magistério Superior e o do Ensino Básico, Técnico e Tecnológico, em que pese a vigência do mecanismo da RSC, conforme já discutido neste trabalho. Isonomia dos servidores Técnico-Administrativos de ambas as Instituições, nesse caso tratando-se da mesma carreira. Mesma política de contratação de pessoal vinculado às áreas de vigilância, limpeza e manutenção, sob o regime de terceirização. E, por último, não obstante tratar-se de uma rede ligada tradicionalmente à Educação Profissional, passa no período pós-reestruturação a atuar fortemente na Educação Superior, inclusive no âmbito da Pós-graduação.

Outro aspecto que se deve ponderar na análise de tais indicadores diz respeito aos recursos do bloco de investimentos, como componente do cálculo para Gasto Médio Anual e Custo Médio Anual por estudante da Rede. Ou seja, pela própria característica dos elementos de despesas desse bloco - edificações e aquisições de equipamentos de laboratórios, os quais se constituem em bens de capital que serão utilizados por décadas - implicando apenas em custos de manutenção, de modo que os recursos aplicados ao longo da expansão da Rede Federal de ECPT serão diluídos ao longo dos anos, e não apenas no ano de apuração dos indicadores.

\section{CONSIDERAÇÕES FINAIS}

No já distante ano de 1988, quando as mudanças advindas das transformações observadas na economia mundial começavam a aportar no Brasil, por meio da implementação de um novo doutrinário econômico-políticosocial, Francisco de Oliveira (1988) assinalava o que chamou de crise do padrão de financiamento público. Nesse ensaio, o autor indicava que não obstante a retomada, desde os anos 1970, nos países centrais dos pressupostos liberais que minimizam as funções sociais do Estado, estava claro o caráter ex-ante do papel do fundo público em relação às demandas de reprodução do capital, ou seja, a utilização de parte dos recursos do fundo público pelos capitais particulares se constituía como condicionante da própria reprodução do capital.

Assistiu-se, a partir de então, segundo o autor, a um movimento que, ao mesmo tempo em que escamoteava o caráter fundamental do fundo público pelos empresários, tratava de demonizar o gasto público como responsável pelos 
déficits das contas públicas. Nesse sentido, a hegemonia conservadora, sobretudo do início da década de 1990, começa a implementar no país uma agenda de reformas de tipo neoliberal, por meio da qual o Estado passava a eximir-se do seu papel social, comprometendo, inclusive, a concretização da maior parte do pacto político-social estabelecido na Constituição de 1988.

O campo da educação, e particularmente a modalidade da Educação Profissional, foi duramente impactado por tais medidas. Realizada pelo Decreto $n^{\circ} 2.208$ de 17 de abril de 1997, sob uma elaboração discursiva que apelava para a necessidade do aumento da produtividade, da empregabilidade, da eficiência, a reforma da EP do governo Fernando Henrique Cardoso, foi responsável pela desestruturação das ofertas mais consistentes de Educação Profissional integrada ao Ensino Médio, precisamente na antiga Rede Federal, bem como por promover a privatização e a precarização dos cursos na modalidade (MANFREDI, 2002).

Com a exaustão do modelo representado pela radicalização do Estado mínimo implementado até o governo FHC, tem-se a ascensão de uma nova hegemonia política, que, não obstante tenha mantido os pilares das políticas econômicas então vigentes, procurou mediar os interesses em disputa por meio de políticas sociais que visavam a atenuar os índices de exclusão. Tal orientação de política governamental ensejou uma substantiva ampliação do gasto público em educação, da qual resultou o processo de reestruturação da Rede Federal de EPCT, implicando, até o início da crise do desenvolvimentismo, a elevação substancial dos indicadores apurados neste trabalho.

A elevação do gasto médio e do custo médio por aluno da RFEPCT entre os anos de 2009 e 2014, conforme já assinalado, foi determinada pelo processo de expansão física da Rede Federal. A elevação do bloco de investimentos em 670\% entre 2009 e 2013 é bem representativo desse movimento. O processo de expansão também implicou a elevação dos recursos de Despesas Correntes, a exemplo da contratação do quadro de servidores para as novas unidades. Deve-se salientar que, dada a dinâmica do processo de expansão, é de se esperar que, nos primeiros anos, o gasto médio e custo médio tendem a elevar-se, dentre outros fatores, pela subutilização do potencial produtivo dos recursos humanos. A título de ilustração do que se afirma, tem-se a abertura de determinados campi e cursos, cujos docentes são contratados no início da oferta, de modo que, no primeiro ano de curso, parte expressiva da carga horária do profissional ficará ociosa, uma vez que não há turmas suficientes para absorvê-la. A mesma lógica se aplica a outros segmentos de servidores técnico-administrativos e, mesmo, de pessoal terceirizado. Tem-se desse modo, portanto, que, passados os primeiros anos, os indicadores de gasto e custo-aluno tenderiam a apresentar sensíveis reduções 
em relação aos primeiros anos da expansão da Rede. Contudo, o movimento observado entre 2015 e 2016 passa ao largo de tal lógica de acomodação dos indicadores.

A retração observada nos indicadores de gasto médio e custo médio por aluno da Rede Federal de EPCT resulta do movimento de redução dos recursos de Despesas Correntes e Investimentos conforme já mostrado neste estudo, assinalando uma tendência de queda a partir do ano de 2015. A brusca retração dos recursos e, consequentemente, a redução dos indicadores de gasto médio e custo médio por aluno a partir deste ano expressa um movimento de reorientação da relação do fundo público com os gastos sociais no país, num contexto de agravamento de uma profunda crise político-econômica que ganha corpo com a reeleição da presidenta Dilma Rousseff em 2014.

Tem-se, no entanto, que o movimento de expansão do gasto-médio e do custo-médio dos estudantes da RFEPCT observado neste estudo se apresenta como contradição da tendência geral da sociedade brasileira, inserida no quadro geral do atual estágio de acumulação capitalista global. Tal movimento, situa-se, precisamente, no contexto da disputa pelos recursos do fundo público conforme assinalado por Oliveira (1988), e se supõe que provavelmente só se efetivou num contexto de negociação, por meio da qual os setores privados tiveram farto acesso à volumosas frações de recursos públicos, em vista do financiamento da Educação Profissional mercadológica, mas também, e sobretudo, da Educação Superior privada, por meio de programas federais, tais como o Programa de Financiamento Estudantil (FIES), Programa Universidade para Todos (Prouni) e Programa Nacional de Acesso ao Ensino Técnico e Emprego (Pronatec).

\section{REFERENCIAS}

AMARAL, Nelson Cardoso; PINTO, José Marcelino de Rezende. O financiamento das IES brasileiras em 2005: recursos públicos, privados e custo dos alunos. SérieEstudos, Periódico do Programa de Pós-Graduação em Educação da UCDB. Campo Grande/MS, n. 30, p. 51-70, jul./dez.2010.

BRASIL, Ministério da Educação. Plataforma Nilo Peçanha. PNP 2018, vol. 2. Disponível em: http://resultados.plataformanilopecanha.org/2018/. Acesso em: Maio de 2019.

. INEP. Sinopses Estatísticas da Educação Superior 2016, Brasília, 2017. http://portal.inep.gov.br/web/guest/sinopses-estatisticasda-educacaosuperior. Acesso em: outubro de 2017. 
Sinopses Estatísticas da Educação Superior 2015, Brasília, 2017. http://portal.inep.gov.br/web/guest/sinopses-estatisticasda-educacao-superior. Acesso em: outubro de 2017.

Sinopses Estatísticas da Educação Superior 2014, Brasília, 2017. http://portal.inep.gov.br/web/guest/sinopses-estatisticasda-educacao-superior. Acesso em: outubro de 2017.

Sinopses Estatísticas da Educação Superior 2013, Brasília, 2017. http://portal.inep.gov.br/web/guest/sinopses-estatisticasda-educacao-superior. Acesso em: outubro de 2017.

Sinopses Estatísticas da Educação Superior 2012, Brasília, 2017. http://portal.inep.gov.br/web/guest/sinopses-estatisticasda-educacao-superior. Acesso em: outubro de 2017.

Sinopses Estatísticas da Educação Superior 2011, Brasília, 2017. http://portal.inep.gov.br/web/guest/sinopses-estatisticasda-educacao-superior. Acesso em: outubro de 2017.

Sinopses Estatísticas da Educação Superior 2010, Brasília, 2017. http://portal.inep.gov.br/web/guest/sinopses-estatisticasda-educacao-superior. Acesso em: outubro de 2017.

Sinopses Estatísticas da Educação Superior 2009, Brasilia, 2017. http://portal.inep.gov.br/web/guest/sinopses-estatisticasda-educacao-superior. Acesso em: outubro de 2017.

Sinopses Estatísticas da Educação Superior 2008, Brasília, 2017. http://portal.inep.gov.br/web/guest/sinopses-estatisticasda-educacao-superior. Acesso em: outubro de 2017.

Censo escolar da educação básica 2015. Brasília, DF: INEP/MEC, 2016.

Censo escolar da educação básica 2014. Brasília, DF: INEP/MEC, 2015. 
. Censo escolar da educação básica 2013. Brasília, DF: INEP/MEC, 2014.

. Censo escolar da educação básica 2012. Brasília, DF: INEP/MEC, 2013.

. Censo escolar da educação básica 2011. Brasília, DF: INEP/MEC, 2012.

. Censo escolar da educação básica 2010. Brasília, DF: INEP/MEC, 2011.

- Instituto Federal de Educação, Ciência e Tecnologia: um novo modelo em educação profissional e tecnológica. Concepção e Diretrizes. Brasília: MEC, 2010.

. Censo escolar da educação básica 2009. Brasília, DF: INEP/MEC, 2010.

. Instituto Nacional de Estudos e Pesquisas Educacionais Anísio Teixeira (INEP). Censo escolar da educação básica 2008. Brasília, DF: INEP/MEC, 2009.

. Lei $\mathrm{n}^{\circ}$ 9394, de 20 de dezembro de 1996. Estabelece as Diretrizes e Bases da Educação Nacional. 1996. Disponível em: http:/ /www.planalto.gov.br/ ccivil_03/_ato2007-2010/2008/lei/111892.htm . Acesso em 20 jun. 2016.

. Lei $\mathrm{n}^{\circ}$ 11.892, de 29 de dezembro de 2008. Institui a Rede Federal de Educação Profissional, Científica e Tecnológica, cria os Institutos Federais de Educação, Ciência e Tecnologia, e dá outras providências. Diário Oficial da União, Brasília, p. 1, 30 dez. 2008.

. Decreto $\mathbf{n}^{\circ}$ 5.154, de 23 de julho de 2004. Regulamenta o $\int 2^{\circ}$ do art. 36 e os arts. 39 a 41 da Lei no 9.394, de 20 de dezembro de 1996, que estabelece as diretrizes e bases da educação nacional, e dá outras providências. Disponível em http://www.planalto.gov.br/ccivil_03/_ato2004-2006/2004/decreto/d5154. htm acesso em 20 de set. 2016. 
Decreto-Lei $\mathbf{n}^{\mathbf{0}} \mathbf{2 . 2 0 8 / 9 7}$, de 17 de abril de 1997. Regulamenta o $\int$ $2^{\circ}$ do art. 36 e os arts. 39 a 42 da Lei $n^{\circ}$ 9.394, de 20 de dezembro de 1996, que estabelece as diretrizes e bases da educação nacional. 1997. Disponível em: http://www.planalto.gov.br/ccivil_03/decreto/D2208.htm . Acesso em 28 jan. 2015.

Constituição da República Federativa do Brasil, 1988b. Disponível em: http://www.legislação.planalto.gov.br . Acesso em 27 dez. 2015.

MANFREDI, S. M. Educação profissional no Brasil. São Paulo: Cortez, 2002.

OLIVEIRA, Francisco de. O surgimento do antivalor. In: Novos Estudos, Cebrap no 22.,1988.

PEREIRA, Josué Vidal. O Financiamento da Rede Federal de Educação Profissional, Científica e Tecnológica. 2018, 276 p. Tese (Doutorado em Educação) - Goiânia: Universidade Federal de Goiás, 2018.

JOSUÉ VIDAL PEREIRA é Professor do Instituto Federal de Educação de Goiás, Doutor em Educação (UFG) e Mestre em Educação (UnB). E-mail: josue. pereira@ifg.edu.br

ORCID: https://orcid.org/0000-0003-0210-3137

Recebido em maio de 2019

Aprovado em junho de 2019 